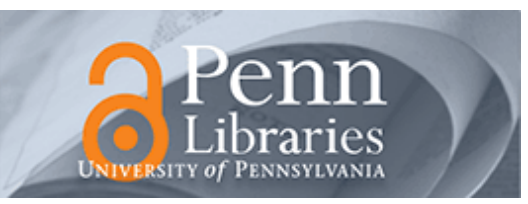

University of Pennsylvania

ScholarlyCommons

$9-21-2012$

\title{
Variability in Demand for Special Education Teachers: Indicators, Explanations, and Impacts
}

\author{
Erling E. Boe \\ University of Pennsy/vania, boe@gse.upenn.edu \\ Laurie U. deBettencourt \\ James Dewey \\ Michael Rosenberg \\ Paul Sindelar
}

See next page for additional authors

Follow this and additional works at: https://repository.upenn.edu/gse_pubs

Part of the Education Economics Commons, and the Special Education and Teaching Commons

\section{Recommended Citation}

Boe, E. E., deBettencourt, L. U., Dewey, J., Rosenberg, M., Sindelar, P., \& Leko, C. (2012). Variability in Demand for Special Education Teachers: Indicators, Explanations, and Impacts. Retrieved from https://repository.upenn.edu/gse_pubs/245

Boe, E. E., deBettencourt, L. U., Dewey, J., Rosenberg, M., Sindelar, P., \& Leko, C. (2013). Variability in demand for special education teachers: Indicators, explanations, and impacts. Exceptionality: A Special Education Journal, 21(2), 103-125. doi: 10.1080/09362835.2013.771563

This is an Author's Accepted Manuscript of an article published in Exceptionality: A Special Education Journal, 2013, (C) Taylor \& Francis, available online at: http://www.tandfonline.com/10.1080/09362835.2013.771563.

This paper is posted at ScholarlyCommons. https://repository.upenn.edu/gse_pubs/245

For more information, please contact repository@pobox.upenn.edu. 


\title{
Variability in Demand for Special Education Teachers: Indicators, Explanations, and Impacts
}

\begin{abstract}
After decades of growth, the number of special education teachers (SETs) has begun to decline. In 2009, U.S. schools employed $13 \%$ fewer SETs than in 2006. The number of annual new hires of SETs also dropped dramatically in some states. The onset of these declines predated the economic downturn of 2008 and resulted in part from a steady decline since 2005 in the number of students with disabilities (SWD) served. We consider factors that may be contributing to declining demand for SETs, among them the number of SWD, service delivery, the economic downturn, and present supporting evidence. We also consider the potential impact of reduced demand on SET supply, teacher education, equitable distribution of teachers, and, most importantly, outcomes for SWD. We call for vigilance and monitoring of SET employment data to assure that all students receive the appropriate education to which they are entitled.
\end{abstract}

\section{Keywords}

special education teachers, teacher supply and demand, employment trends

\section{Disciplines}

Education | Education Economics | Special Education and Teaching

\section{Comments}

Boe, E. E., deBettencourt, L. U., Dewey, J., Rosenberg, M., Sindelar, P., \& Leko, C. (2013). Variability in demand for special education teachers: Indicators, explanations, and impacts. Exceptionality: A Special Education Journal, 21(2), 103-125. doi: 10.1080/09362835.2013.771563

This is an Author's Accepted Manuscript of an article published in Exceptionality: A Special Education Journal, 2013, @ Taylor \& Francis, available online at: http://www.tandfonline.com/10.1080/ 09362835.2013 .771563$.

\section{Author(s)}

Erling E. Boe, Laurie U. deBettencourt, James Dewey, Michael Rosenberg, Paul Sindelar, and Christopher Leko 


\title{
Variability in Demand for Special Education Teachers: Indicators, Explanations, and Impacts ${ }^{1}$
}

\author{
Erling E. Boe \\ University of Pennsylvania \\ Laurie U. deBettencourt \\ Johns Hopkins University \\ James F. Dewey \\ University of Florida \\ Michael S. Rosenberg \\ SUNY New Paltz \\ Paul T. Sindelar \\ Christopher D. Leko \\ University of Florida
}

September 21, 2012

In press: Exceptionality

${ }^{1}$ The first five authors are listed alphabetically to reflect equal contributions to the paper. 


\begin{abstract}
After decades of growth, the number of special education teachers (SETs) has begun to decline. In 2009, U. S. schools employed 13\% fewer SETs than in 2006. The number of annual new hires of SETs also dropped dramatically in some states. The onset of these declines predated the economic downturn of 2008 and resulted in part from a steady decline since 2005 in the number of students with disabilities (SWD) served. We consider factors that may be contributing to declining demand for SETs, among them the number of SWD, service delivery, and the economic downturn, and present supporting evidence. We also consider the potential impact of reduced demand on SET supply, teacher education, equitable distribution of teachers, and, most importantly, outcomes for SWD. We call for vigilance and monitoring of SET employment data, to assure that all students receive the appropriate education to which they are entitled.
\end{abstract}

Key Words: special education teachers, teacher supply and demand, employment trends 
Variability in Demand for Special Education Teachers:

Indicators, Explanations, and Impacts

For well over two decades as the demand for special education teachers (SETs) was increasing in response to rapid growth in the numbers of students with disabilities (SWD), the field struggled to address shortages of qualified teachers to satisfy this demand (Boe, 2006). ${ }^{2}$ The Office of Special Education Programs (OSEP) issued annual reports on the numbers of fully certified (and recently, highly qualified) SETs employed in U. S. schools. Analyses of these trend data from OSEP and from the National Center for Education Statistics (NCES) by Boe and colleagues (e.g., Boe, 2006; Boe \& Cook, 2006; Boe, Cook, \& Sunderland, 2007; Cook \& Boe, 2007) have demonstrated that increases in demand outstripped the supply of qualified SETs resulting in acute and chronic shortages—shortages that persisted in spite of OSEP's longstanding commitment to and investment in personnel preparation (West \& Whitby, 2008).

However, recent and substantial evidence (presented below) shows that the historical trend of continuously increasing demand for SETs ended in 2005, and, in fact, began to decline gradually. Given this unprecedented reversal in the demand for SETs, the purposes of this paper are first to present empirical evidence for the recent decline in demand and then to provide a conceptual framework for understanding it. We then offer evidence-based and testable hypotheses for explanations of this decline and for its impact on the field of special education.

Other than reporting substantial empirical evidence demonstrating the recent decline in SET demand, this is primarily a theoretical and discussion paper intended to foster awareness of (a) the reversal in the historical trend of increasing demand for SETs and (b) its potential farreaching consequences for the field of special education and ultimately for outcomes of SWD. Our framework for conceptualizing explanations for, and impacts of, the current decline in SET 
demand is designed to serve a heuristic function. Though we present some empirical evidence for the elements of the framework, this evidence in the context of the framework is suggestive of promising and important lines of future inquiry, instead of being sufficient and conclusive evidence. To inform policy making about the teaching force in special education, it is important that the current trend of declining demand for SETs be monitored closely, and that new research is initiated that focuses on its potential causes and impacts.

Evidence for the recent decline in demand for SETs is presented next, followed by our conceptual framework for contextualizing this decline. In later sections, we offer evidence-based hypotheses for explaining the decline in demand and for its potential impacts on major aspects of the field of special education.

\section{Indicators of the Declining Demand for SETs}

The recent decline in teacher demand has been making headlines. In May 2009, the New York Times reported that the New York City Public Schools stopped hiring new teachers from outside the system — after hiring 5,725 teachers the year before, many of them SETs (Hernandez, 2009, May 10). A year later, philly.com (Graham, 2011, August 16) reported that the Philadelphia School District expected to employ 1,261 fewer teachers in 2011-2012 than in 2010-2011, of which 232 were SETs. Evidence of the pervasiveness of these employment trends may be also seen in recent surveys conducted by the Center on Education Policy (CEP) (Kober \& Rentner, 2011) and the American Association of School Administrators (AASA) (McCord \& Ellerson, 2009). In the AASA survey, 66\% of the district administrators surveyed reported cuts in all teaching positions in 2009-10, and 83\% predicted that additional positions would be eliminated in 2010-11. 
Although stimulus funding under the American Recovery and Reinvestment Act (ARRA) allowed many districts to postpone or minimize layoffs beginning with school year 2009-10, the availability of such funds will decline as they are expended and end in the 2011-12 school year.. The prospect of large-scale layoffs since 2009-10 then has become reality again. A 2010 AASA study estimated that 275,000 jobs would be cut from the education system nationwide in 20102011 (Vogt, 2010, May 4). According to a recent report from the Executive Office of the President (2012), 300,000 education jobs (a large, but indeterminate, percentage of which have been teaching positions) have been cut in the three school years following the end of the recession in June 2009, and considerably more layoffs of educators are expected for the 2012-13 school year.

Similar declines in SET employment have been reported. In Michigan, for example, the Lansing School District proposed laying off 14\% of SETs who provide daily instruction in special education classrooms (Thomas, 2010, December 17). In New Haven, Connecticut, the Superintendent of Schools proposed increasing caseloads, so that the district's special education needs could be met with 25\% fewer SETs (DeMatteo, 2011, June 14). As reviewed below, such cutbacks in special education teaching positions have been corroborated by objective teacher demand statistics drawn from several national and state databases. This evidence makes clear that the recent decline in demand for SETs has been both substantial and widespread.

\section{Total Demand}

In general, the demand for teachers in public schools is the number that school districts want to employ and are prepared to compensate at a given time (Barro, 1992). In special education, this is represented by the total demand for SETs in public schools as measured by the number of teachers employed with a main assignment in special education. To be precise, the number of 
funded, but vacant, teaching positions (once a school year commences) should be added to the number of SETs employed to compute total demand. Fortunately, only about one percent of SET positions have been vacant, as indicated by evidence from national databases during the 1990s (Boe, 2006). This percent of vacant positions was considered to be so negligible that the collection of such vacancy data was discontinued. It is reasonable to expect a small vacancy percentage because individuals, who have not completed either teacher preparation or qualified for full certification, have been hired to fill vacancies when there is a shortage in the supply of qualified SETs (Boe \& Cook, 2006). In view of small percentage of vacancies, using the number of employed SETs as an indicator of total demand entails little error (and represents the only type of estimates of demand currently available). ${ }^{3}$

Based on OSEP data (annual Tables 3-2 at www.ideadata.org), the long-term trend of increasing national total demand of SETs peaked in 2005, and then decreased by $13 \%$ from fall 2005 through fall 2010, or by over 55,000 SETs (See Figure 1). ${ }^{4}$ The decreasing demand through 2008 preceded the onset of the economic downturn late in 2008. It is to be expected that the total demand for SETs in 2009 would have declined substantially from the level seen in Figure 1 were it not for federal stimulus funding under the ARRA. This infusion of funds saved or created over 54,000 jobs in special education nationally_a considerable (but unknown) percentage of which were for teachers (U.S. Department of Education, 2010). Once the initial impact of stimulus funds on saving jobs in 2009 diminished, the demand for SETs dropped again for 2010.

Corroborating evidence of the decline in the demand for SETs is seen in data from the national Schools and Staffing Survey (SASS) conducted by the NCES. Based on SASS, the number of SETs (full and part-time) declined from 414,200 in 2003 (Boe, 2008) to 394,600 in 2007 (E. Carlson, personal communication, August 23, 2012), a 4.7\% decline. Based on OSEP 
data (www.ideadata.org), the number of full-time equivalent SETs declined from 408,800 in 2003 to 390,400 in 2007, also a 4.7\% decline.

Although the demand for SETs has declined since 2005, the demand for general education teachers (GETs) continued to increase annually to over 2,800,000 through fall 2008 and remained at this level in 2009. ${ }^{5}$ It was not until 2010 that the demand for GETs declined by 92,000 (3.3\%). Based on this evidence (and as reviewed below), it is apparent that some of the factors driving total demand for SETs, in recent years at least, are not the same, or not as strong, as those driving the total demand for GETs.

\section{Annual Demand}

In analyzing teacher demand, it is important and useful to distinguish between total demand (as reviewed above) and annual demand for SETs, because each provides a different perspective and each is satisfied by distinctive sources of teacher supply. While the total demand is measured by the number of all employed SETs, the annual demand is defined by the number of teaching positions each year that become vacant and need to be filled by the recruitment of SETs from various sources of supply. ${ }^{6}$ At the district and state levels, counts of newly-hired SETs each year represent a major indicator of annual demand.

In Florida, for example, the number of newly hired SETs declined 62\% from fall 2005 through fall 2009 (Florida Department of Education, 2009) (see Figure 2). This steep decline was not concentrated in a particular region of the state or limited to a few districts. Instead, it was a statewide phenomenon, with 64 of 67 total counties reporting decline during this 5-year period (Florida Department of Education). A similar trend occurred in Maryland, where the number of newly hired SETs declined from 823 in 2007 to 417 in 2009, a 49\% decrease (Maryland State Department of Education, 2010). The Georgia Professional Standards Commission (2010, March 
23) reported that new SET hires in that state dropped to 1,350 in 2010, down 58\% from 2008, when it peaked at 3,232. Such data indicate that the job market in special education for newlyprepared novice teachers and for experienced teachers in the reserve pool has contracted sharply, at least in these states. The lack of current national data on the annual demand for SETs, as well as the lack of data from additional states, attests to the need for more systematic data collection and analysis. Since new hires represent the demand for the products of teacher education programs, such data will be useful in planning program development and possibly retrenchments.

\section{Reduced Demand}

In sum, compared to the decades-long trend of unmet demand for SETs, our field is now experiencing reduced SET employment nationally, and, in some states so far as we know, fewer SETs are newly hired each year. In and of itself, employment of fewer SETs is neither positive nor negative. Reduced demand may result from widespread and successful implementation of interventions (e.g., Reading First) that minimize the need for special education. On the other hand, fewer SETs may be employed because schools with significantly diminished resources cannot afford to provide special education services to as many SWD as they have in the past. In this case, some eligible students may be denied a free appropriate public education, or their teachers may be so overburdened that they are unable to provide as much individualized instruction.

These are real and serious concerns. As a result, we believe it is imperative to understand fully the factors affecting SET demand and the impact of declining demand on key outcomes. In order to advance such understanding, we present next a conceptual framework that portrays and organizes factors that we hypothesize influence SET demand and aspects of special education that may be impacted by it. 


\section{Conceptual Framework}

Our conceptual framework is presented in Figure 3. The circle at its center represents demand for SETs. We hypothesize that four factors—-number of SWD, prevailing service delivery models, special education funding, and teacher attrition represented across the top of the framework-influenced variability in demand. As seen in the lower part of the framework, we also hypothesize that variability in demand is likely to impact on four aspects of special education-(a) outcomes for SWD, (b) teacher education enrollments, (c) the equitable distribution of teachers within states, and (d) SET supply.

In the sections that follow, we elaborate on each component of this framework, and provide available evidence for explanations of the recent decline in the demand for SETs, and for the potential impacts of this decline on the field of special education.

\section{Influences on SET Demand}

In this section, four factors are considered that we hypothesize influence demand for SETs: the number of SWD, service delivery, special education funding, and SET attrition. In these sections, where pertinent, we also discuss the general economic decline and the indirect impact it exerts on total demand.

\section{Number of SWD}

In general, the demand for teachers is directly related to the number of students. Since the demand for SETs has declined substantially as shown above, it is reasonable to expect that the number of SWD has also declined — a trend observed in national and state data. For the analysis presented here, we use national data on the number of SWD defined by OSEP as the number of students ages 6 through 21 served under IDEA (annual Tables 1-3 at www.ideadata.org). On the

left axis in Figure 4, we display the number of SWD in the U.S. from 2000 through 2009 and, on 
the right axis, the number of SWD in Florida. We use Florida as an exemplar because it is a large state (6\% of the U.S. population) and an early adopter of strong education accountability measures. The number of SWD in the U. S. climbed steadily from 2000 to 2004, and then fell 4\% from 2004 to 2009. In Florida, the number of SWD climbed from 2000 to 2005 and then fell $8 \%$ from 2005 to 2009.

Interestingly, the decline in the number of SWD has little to do with change in total K-12 enrollment. The rapid growth in the school age population in the 1990s - the baby boom echocaused a surge in demand for teachers, which contributed significantly to shortages of SETs (NCES, 1997). In contrast, the size of the school age population was stable from 2000 to 2010 and annual changes in enrollment were much smaller than in the 1990s. On the other hand, the ratio of SWD to enrollment, or the prevalence of disabilities, peaked at 12.54 SWD per 100 public PK-12 students in 2004, dropped below its 2000 level in 2007, and fell to 11.91 by 2009. The decline started earlier in Florida and was larger, with the ratio falling from 15.6 SWD per 100 public PK-12 students in 2002 to 14.1 in 2009—a decline of 10\%. Moreover, the decline has not been proportional across disability categories. The number of students with specific learning disabilities (SLD) fell steadily from 2000 through 2008 (abstracted from www.ideadata.org , 2000-2008), while the total of all other categories rose every year, before falling 1\% in 2008 .

\section{Service Delivery}

Although we cannot pinpoint with certainty why there are fewer SWD overall, and fewer students with SLD in particular, the success of programs such as Reading First (RF) and response to intervention (RTI) offer potential explanations. RF provided early, intensive reading instruction intended to mitigate the problems children experience learning to read. For example, Torgesen (2009) reported that in Florida SLD identification fell by $81 \%$ in kindergarten and 67\% 
in first grade in the first 3 years of RF implementation. If RF implementation in fact reduced SLD identification, a measure of RF implementation across states should correlate with changes in the number of students with SLD. To test this possibility, we regressed the average annual change in the number of students with SLD per 1000 public K-12 students from 2004 to 2008 on the percentage of elementary schools in which RF was implemented by state as of 2007. We found a moderate and statistically significant negative effect. The coefficient of $-0.855(r=$ $-0.32, p=0.024)$ indicates that, on average, a $10 \%$ increase in the number of elementary schools implementing RF was associated with an annual decrease of approximately 1 student with SLD per 1,000 public K-12 students. This analysis suggests that the success of RF may account for at least some of the reduction in students with SLD.

Fuchs, Fuchs, and Compton (2012) argued that the purpose of RTI is "not to prevent special education placement,” but to prevent “inadequate academic performance” and its "lifelimiting sequelae” (p. 270). In this sense, RTI shares with RF an emphasis on early intervention and intent to mitigate learning difficulties, in this case through increasingly intensive levels of support. Logically, successful implementation of RTI, like implementation of RF, should reduce the number of students who require intensive interventions, and less intensive intervention may mean reduced demand for SETs. To test this logic, we used two of the four implementation categories developed by Zirkel and Thomas (2010) to differentiate among states on RTI implementation. In one, RTI implementation was mandatory, and SLD classification via RTI replaced classification based on severe discrepancy (SD). In the other, RTI implementation was not mandatory.

We used 2004 and 2008 OSEP Child Count data to compute change in SLD prevalence by state and compared the size of the reduction in states that required and did not require RTI 
implementation. Unfortunately, of the seven states Zirkel and Thomas (2010) identified as requiring RTI, only three had begun doing so before 2008. Even so, SLD prevalence declined by 2.53 per 1,000 public K-12 students annually from 2004 to 2008 in the three states requiring RTI and eliminating SD, compared to 1.76 in the 37 states that did not, a difference that is almost significant for a one tail test $(p=0.126)$.

Although this analysis is far from conclusive, the magnitude of this difference (corresponding to an effect size of 0.695) suggests that RTI implementation may indeed reduce the number of students that schools identify as having SLD. Several studies and reviews (e.g., Barton \& Stepanak, 2009; Dexter, Hughes, \& Farmer, 2008; VanDerHeyden, Witt, \& Gilbertson, 2006; Vaughn, Wanzek, Linan-Thompson, \& Murray, 2007; Vellutino, Scanlon, Small, \& Fanuele, 2006) have found that RTI can reduce the number of students who are referred for special education services, as well as increase their academic performance. For example, VanDerHeyden et al. found that, in one Arizona district, implementation of tiered instructional procedures resulted in special education referrals dropping by approximately $50 \%$.

Implementation of RTI and other tiered service delivery systems has become widespread. Although no single model is recognized as a standard, all entail demanding new roles for classroom teachers and SETs (Brownell, Sindelar, Kiely, \& Danielson, 2010; Fuchs et al., 2012). Demand for SETs may be influenced by such role changes. For example, the success of RTI implementation hinges on the ability of GETs to accommodate struggling students. Thus, successful implementation in and of itself may reduce the need for SETs.

To assess the combined effects of RF and RTI implementation, we used regression analysis to predict change in SLD prevalence using as predictors (a) percentage of RF 
implementation and (b) a dummy variable to differentiate between states that mandated RTI and states that did not. Both the overall downward trend and the impact of RF were statistically significant at conventional levels. Although only three states mandated RTI, the effect of RTI implementation reached statistical significance (at the 10\% level) as well. These findings are merely suggestive-much more work is needed to take advantage of additional data as they become available_-but they are interesting. Rounding to one decimal, the results suggest a state implementing RF in $10 \%$ of its elementary schools along with RTI could experience an annual decline of 3 students with SLD per 1,000 public K-12 students. SLD identifications made prior to RTI implementation are not simply vacated upon RTI implementation. Since it takes 13 years for a cohort complete all grades from kindergarten through twelfth, it follows that the full impact of RTI implementation on SLD prevalence will not be felt until the thirteenth year of implementation (ignoring identifications from pre-kindergarten and retentions). Therefore, any annual declines in SLD prevalence related to RTI implementation may well continue for a number of years.

In addition to programs such as RF and RTI, identification of SWD may be affected by state funding formulas (Cullen, 2003; Minow, 2001). A 1994 survey conducted by the Center for Special Education Finance found many states were implementing special education finance reform and that most others were considering doing so in the 1990s (OSEP, 1995). Survey respondents cited inappropriate fiscal incentives leading to over-identification and unnecessarily restrictive placements as one of their main concerns. Thus, the decline in SLD prevalence since 2000 may reflect the long term affects of funding reforms intended to address over-identification and misplacement.

\section{Special Education Funding}


Another explanation for the recent decline in both total demand and annual demand for new SET hires is a shortage of funds available for teaching positions in special education. State and local tax revenues used to fund education budgets depend heavily on economic performance, and economic recovery is proceeding slowly. Real Gross Domestic Product (GDP) per capita remains well below potential, with the economy unlikely to recover to near full employment until 2015 or after (Board of Governors of the Federal Reserve System, 2011; Congressional Budget Office, 2011). The reduction in GDP translates directly to reductions in state and local tax revenues.

There is ample evidence that schools are struggling to make ends meet. The latest survey in a series conducted by the AASA indicates that the efforts to avoid cutting teachers were shortlived, and the reduction in personnel will continue over the next several years (Ellerson, 2010a). Nearly half (48\%) of the school districts surveyed reported they had laid off personnel in 201011, and two thirds (66\%) anticipated doing so in 2011-12 (Ellerson). In some districts, layoffs were avoided by natural attrition: teachers who retired or left and were not replaced.

Federal stimulus funding allocated to states in 2009 is reported to have saved or created 409,000 jobs, including 54,000 in special education (U. S. Department of Education, 2010). Education Week recently estimated that states spent $\$ 100$ billion in stimulus funding on education (Cavanagh, 2011); however, these funds will not last indefinitely. Only 10\% of a nationally representative sample of school districts reported having unspent State Fiscal Stabilization Fund resources available for the 2011-2012 school year (Kober \& Rentner, 2011), and percentages of districts with funds from other ARRA programs available to spend in 201112 were no higher. According to the report, the most common use of ARRA funds was to save or create jobs, and $83 \%$ of responding districts reported having done so. While the federal aid has 
greatly helped to stabilize education budgets, it has not eliminated layoffs or postponed all layoffs indefinitely (Kober \& Rentner; McCord \& Ellerson, 2009).

ARRA funds attenuated what would otherwise have been an even steeper decline in demand for teachers during 2009 and 2010 (e.g., Kober \& Rentner, 2011). The unfortunate truth remains that hundreds of thousands of education jobs underwritten by stimulus dollars may be lost in 2011 (Hess \& Downs, 2010). The loss of ARRA stimulus funding and continued budget constraints at the state and local levels inhibit schools from recovery and, more immediately, foreshadows more job cuts and fewer personnel resources (Ellerson, 2010b).

\section{SET Attrition}

The attrition of SETs from teaching employment is a major component driving the annual demand for recruitment of SETs to fill vacant positions. ${ }^{6}$ Thus, if the rate of attrition declines, so will the annual demand for SETs decline (as illustrated in Figure 2 by the falling numbers of newly-hired teachers). In the 2000-2001 and 2004-2005 Teacher Follow-up Surveys (TFS), annual SET attrition nationally reached 9\%-10\% (about 26,000 SETs)-levels considerably higher than seen in the 1980s and 1990s (Boe, Cook, \& Sunderland, 2009). According to results from the 2008-09 TFS, teacher attrition rates remained at the level seen in 2004-2005 (Keigher, 2010).

Unfortunately, more recent data on national-level teacher attrition rates will not become available until the next administration of the TFS in 2012-2013. Still, there is evidence from several sources of reduced attrition rates following the economic downturn late in 2008. For example, the Charlotte-Mecklenburg School District lost only $11.7 \%$ of its teachers in 2009-10 (the sum of teachers leaving teaching employment and moving to teaching positions in other 
districts) compared with 21.8\% eight years earlier. Likewise, attrition statewide in Virginia declined from 14\% to 11\% during the same time (Helms, 2011, July 5).

This is consistent with declining national rates in recent years of annual voluntary attrition (i.e., excluding reductions in force) of employees from corporations according to surveys conducted by the Bureau of National Affairs (BNA) (2008, 2011). From 2007 to 2010, attrition rates of employees in all business and non-business fields declined by 36\%. During these years, the annual attrition for just non-business employees declined by $27 \%$ - a sector that includes teachers (BNA). These reductions in voluntary turnover rates are credible because they exclude reductions in force. Otherwise, we would likely see large increases in attrition.

Thus, it is plausible that the observed decline in annual demand for SETs is partly attributable to reduced SET attrition rates in recent years. The economic downturn that began late in 2008 and has persisted to 2012 is likely to continue to reduce teacher attrition. Many individuals leaving teaching voluntarily do so to retire or to take another job (Boe, Cook, \& Sunderland, 2008). When the job market is tight and fewer jobs are available in the private sector, teachers have less opportunity to leave the field. These conditions currently prevail: For the past 2 years, unemployment rates have hovered at or above 9\%, higher than at any time since the recession of the early 1980s, and jobs were lost every month from 2008 to 2010 (based on data publically available at www.bls.gov ). Economic conditions also influence retirement decisions. The value of retirement savings invested in the stock market declined sharply in 2008 and 2009 before beginning a gradual recovery (data on the S\&P 500, Wilshire 5000, and Dow Jones stock indices are available at http://research.stlouisfed.org/fred2/categories/32255). If a teacher's spouse becomes unemployed or the value of a spouse's retirement account declines, retirement plans may be postponed. Similarly, for many individuals, home equity is a large 
component of savings. A large drop in home values, which in December 2010 were down 31\% from their spring 2006 peak (based on the S\&P Case-Shiller 20-City Home Price Index, available at http://research.stlouisfed.org/fred2/categories/32261 ), means a large drop in retirement savings, in turn influencing decisions to defer planned retirement.

\section{Impact of Declining Demand}

In this section, four factors are considered that we hypothesize are impacted by the declinng demand for SETs: outcomes for SWD, teacher education, the equitable distribution of teachers within and across districts, and SET supply. These four factors make up the bottom row of the conceptual framework (see Figure 3).

\section{Outcomes for SWD}

The lack of satisfactory academic performance by SWD, combined with growing demands for social equity and civil rights, has prompted reconsideration of special education service delivery. As seen in recent years, increasing numbers of SWD have been educated within the context of general education (McLeskey, Landers, Williamson,\& Hoppey, 2010). Combined with economic decline and reductions in SET employment, changes in placement practices have raised concern about outcomes for SWD.Outcomes for SWD are certain to be influenced adversely as fewer SETs are employed, average class sizes increase, support positions (e.g., paraeducators) are eliminated, and caseloads increase,. Caseload increases may be estimated with personnel data from ideadata.org. Thus, although the numbers of both SETs and SWD have decreased, the SWD to SET ratio has increased. In 2005, on average, SETs served 14.3 students; 5 years later, the ratio had grown to 15.7 , a $9.8 \%$ increase (based on data from www.ideadata.org ). As a result, it is likely that SWD receive fewer hours of special education instruction. Such 
changes may adversely affect measures of adequate yearly progress, standardized test performance, and ratings of appropriate social and emotional behavior.

\section{Teacher Education}

Reduced demand for SETs is associated with a downward trend in the percentage of SETs who are not highly qualified. In 2006 (the first year OSEP switched from less than fully certified), $11.2 \%$ of SETs were not highly qualified; in 2010, that percentage was 5.8\%. Notably, the increase in the percent of highly qualified SETs signals movement toward the achievement of a longstanding and overarching goal-access to a qualified teacher. At the same time, however, reduced demand foreshadows change for a field organized around and driven by chronic shortage. Because this change is playing out against a backdrop of serious economic exigency, it brings a sense of urgency and uncertainty to a field that has not seriously considered what to do when its mission is fulfilled. So, what will happen if or when the bottom drops out of the SET demand curve?

The number of newly hired recent graduates may be considered an estimate of demand for the product of teacher preparation. Data reported above indicate that the annual demand for SETs has declined precipitously in both Florida and Maryland. A teacher labor market with declining numbers of jobs and increasing numbers of job seekers offers poor prospects for novice teachers, and discouraging employment prospects could reduce the number of people entering the teacher preparaion pipeline. In turn, enrollment decline may jeopardize the health and sustainability of teacher preparation programs. Faced with budget cuts, colleges of education may have little choice but to eliminate programs, and high-cost, low-enrollment programs may be especially vulnerable. In the past, college of education administrators have questioned the viability of programs that prepare teachers for the blind and visually impaired, the deaf and hard 
of hearing (Johnson, 2003), and students with other low incidence disabilities. Enrollments in such programs have always been low, and where they have survived, colleges often have underwritten their operation. In an era of diminishing state support and serious cost-cutting imperatives, the future of such programs seems tenuous indeed. If they are eliminated, the field may lack adequate training capacity to replenish supply when the economy improves.

Other factors may be contributing to the decline in demand for recent graduates. As we argue elsewhere, the poor economy may have reduced employment mobility and attrition, so that fewer teachers are leaving the field—and thereby creating vacancies. Experienced (but unemployed) teachers seeking to return to work now compete with recent graduates for the pool of available positions that once readily accommodated them all. Furthermore, with the proliferation of entrees to teaching, recent graduates also compete with individuals who lack formal preparation. All of these factors contribute to the difficulty that teacher preparation programs will have in sustaining enrollments and generating sufficient revenue to support themselves. If enrollments in teacher education programs decline-and as other trends (such as deferred retirements) keep employed teachers on the job, perhaps longer than they anticipatedthe consequences for the SET workforce could be significant. For example, with fewer new teachers entering the field annually, the SET workforce will age, and average salaries will increase as a consequence (Roza, Lozier, \& Sepe, 2010, March 16). Where layoffs are necessary, younger, less well-paid teachers, are most vulnerable, and more of them are required to meet a given cost-reduction target.

\section{Equitable Distribution of Teacher Supply}

Although the NCLB Act of 2001 required that all students be taught by highly qualified teachers, demand for them remains unmet in hard-to-staff, high need schools. For example, in 
New York State, high poverty schools were found to have a lower percentage (84.5\%) of teaching assignments filled by highly qualified teachers than low poverty schools (93.6\%) (Brackett, Mundry, Guckenburg, \& Bourexis, 2008). Also, the state’s cities had lower percentages of highly qualified teachers than suburban and rural schools. Similarly, in Philadelphia, Watson (2001) found a greater number of uncertified and inexperienced teachers and higher rates of turnover in schools with higher proportions of poor, minority students than in less diverse, low poverty schools. In terms of special education, Lauritzen and Friedman (1993) reported the simultaneous existence of shortage and excess supply in Wisconsin, sometimes in adjacent districts. In this study, shortages were severe in Milwaukee and in the remote northwest corner of the state, while slight oversupplies were noted in suburban Milwaukee and elsewhere along the Lake Michigan coastline.

The need to address the issue of equitable distribution of highly qualified and highly effective teachers across schools and districts remains critical, as its prominent position among the Secretary of Education’s current priorities for discretionary programs attests (Federal Register, 2010). Reduced demand for SETs and increasing numbers of qualified SETs available for employment represents and emerging opportunity for developing policy solutions to the historical inequities disadvantaging high-need schools. However, excess supply per se does not guarantee that equitable distribution will be achieved or that candidates will take positions in historically hard-to-staff, high-need schools.

\section{SET Supply}

As widely recognized, there has been a chronic shortage in the supply of qualified individuals to fill increasing numbers of teaching positions in special education (Boe, 2006; Boe \& Cook, 2006). With the current decline in demand for SETs, it is expected that the size and 
character of the supply of SETs will be quite different from that seen in prior years (Boe, Cook, Kaufman, \& Danielson, 1996; Cook \& Boe, 2007). For example, the percentage of highlyqualified SETs increased from 91.7\% in 2008 to 94.2\% in 2010 (see annual Tables 3-2 at www.ideadata.org). After the national economic downturn late in 2008, the increase in the supply of highly-qualified SETs as of 2010 indicated that more qualified teachers became available in relation to the deteriorating job market for teachers. This reaction is also represented in a report from Jericho, New York, where 963 applications were received for five teaching positions in special education, a number more than twice that received in prior years (Hu, 2010, May 19).

Some possible changes in teacher supply may improve SET qualifications in the near term. In the intermediate term, other changes may erode our capacity to maintain a qualified teaching force. How each source of supply may be affected by the current decline in SET demand is considered below.

Continuing SETs. With the decreasing demand for SETs and the national job market tight with high unemployment rates since 2009, it is quite possible that the rate of SET retention has increased above its 90\% historical level (Boe et al., 2009). A higher rate of SET retention can occur as a combination of reduced rates of retirement, leaving for personal reasons, leaving for employment opportunities in other fields, and transfers to general education teaching positions (Boe et al., 2008). Because continuing SETs are more likely to be fully qualified than entering teachers (Boe \& Cook, 2006), increased retention of SETs is likely to improve the qualifications of the teaching force. As we mentioned previously, the proportion of not highly qualified SETs has dropped from $11.2 \%$ in 2006 to $5.8 \%$ in 2010. 
Even if the current reduced level of total SET demand continues in the intermediate term, it is likely that this beneficial effect of increased retention will reverse as national employment opportunities improve and as many SETs are no longer able or willing to postpone retirement or to defer leaving for other reasons. A short-term increase in SET retention, followed by increased attrition, represents an ominous instability in the supply of SETs that policymakers should anticipate with contingency plans.

Switching GETs. GETs switching to special education teaching represented a major source of annual teacher supply of new entrants (about 40,000 in 2000 and in 2004; Boe et al., 2008, 2009). This was larger that all other sources of entering teacher supply combined (Cook \& Boe, 2007). With the recent decline in the annual demand for SETs and for GETs, it is reasonable to expect that the supply of GETs seeking to switch to special education will increase relative to the number of open positions in special education.

Reserve pool. The reserve pool is composed of experienced teachers who have left teaching employment and individuals who have completed teacher preparation but delayed entry to employment by a year or more. We know that approximately 16,000 SETs were hired from the reserve pool in 1999, compared with 40,000 employed GETs who switched to special education teaching (Cook \& Boe, 2007; Boe \& Cook, 2008). Although the total size of the reserve pool is not known, it is reasonable to estimate that it has increased as the number of newly hired teachers has declined in recent years (see Figure 2). A growing reserve pool as a potential source of newly-hired SETs represents an asset provided that its members continue to seek teaching employment instead of turn to other employment opportunities if the annual demand for entering SETs continues at a depressed level. 
Newly prepared teachers. In 1999, newly-prepared teachers accounted for almost 7,000 (or 26\%) of entering SETs (Cook \& Boe, 2007). However, as the number of new hires annually in special education has declined in recent years (see Figure 2), the prospect for recent graduates to find teaching employment soon after graduation also has declined. Thus, more recent graduates are likely to enter the ranks of unemployed teachers in the reserve pool. In the short run at least, it is advantageous for special education to have a larger reserve pool from which to recruit entering teachers, and this should continue so long as the production of graduates from teacher education programs does not decline.

Unprepared teachers. When qualified individuals are not available for vacant teaching positions, the fallback option has been to hire individuals who have not been prepared to teach. As of fall 1999, 5\% of entering SETs were unprepared to teach (Cook \& Boe, 2007), and virtually none of them were fully-certified (Boe \& Cook, 2006). So long as the teacher job market is tight, unprepared teachers should not be needed if an increasing number of employed SETs continue in their positions from one year to the next, if the size of the reserve pool increases, and if newly-prepared SETs continue to be produced at the current rate (about 10,000 bachelor’s graduates per year; Cook \& Boe, 2007).

\section{Projecting SWD Enrollment and SET Demand: Two Scenarios}

For informed decision-making, policy makers require some idea of the potential magnitude of change in the SET labor market. In Table 1, we describe two projections of national SET demand that delimit potential change. In the first (or high) projection, we assume that the decline in the prevalence of SWD will continue at a modest pace for 5 years and that the ratio of SETs to SWD will recover (to its 2000 level). In the second (or low) projection, we 
assume that the decline in the prevalence of SWD will continue at a brisk pace for 10 years and that the ratio of SET to SWD will continue to fall.

From these projections, two tentative conclusions seem reasonable. First, total SET demand is unlikely to grow as rapidly as it did in the 1990s. Second, total demand is unlikely to fall below three-quarters of its 2008 level. We may conjecture that significant numbers of new SETs will be needed by 2020 to fill posts vacated largely by retirees. In 2007, roughly one third of public school teachers were 50 or older; by 2020, those teachers who remain in the field will be 63 or older (NCES, 2011). Thus, it is nearly certain that between 2008 and 2020 total attrition of current SETs will be larger than the decline in total SET demand, leading to significant demand for new SETs after economic conditions return to normal (See Table 1).

In the sixth row of Table 1, we estimate the number of SETs hired no later than 2008 and still teaching in 2020. Assuming transfers of SETs to general education and GETs to special education approximately balance out, the seventh row of the table estimates the number of SETs teaching in 2020 hired after 2008 by subtracting SET returning from 2008 from total demand. Given tight budgets and corresponding flat hiring from 2008 to 2011, and given that economic conditions are unlikely to return to normal until 2015 or later (Board of Governors of the Federal Reserve System, 2011, Congressional Budget Office, 2011), it seems likely that a disproportionate number of these new hires will be made after 2015. If we assume all the new hires will be spread approximately evenly over the remaining years and that attrition of new hires is $9.3 \%$ after each of their first 4 years, over 30,000 open SET positions will have to be filled annually in the low scenario and over 55,000 in the high scenario. Moreover, retirements will continue at a brisk pace from 2020 to 2025. Thus, it seems likely that annual demand for SETs will rebound considerably from 2015 to 2025. 


\section{Implications and Recommendations}

In recent years, there has been a substantial decline in the demand for SETs across much of the nation, a decline that has persisted at least to 2010 (see Figure 1). As of the last date for which national data are available in 2010, the demand for SETs had declined by 55,000 since 2005 (or $13 \%$ of the total teaching force in special education). In this section, we identify some implications of this change for special education policy and provide recommendations that follow from these implications.

\section{Education of SWD}

The impact of the recent decline in demand for SETs is likely to have a complex effect on SWDs and the quality of instruction they receive. For one thing, SWD:SET ratios increased by 9.8\%\% from 2005 to 2010. Thus, on average, SETs are working with more students than had been the case the preceding 5 years. On the plus side, the percentage of highly qualified teachers has been increasing steadily since 2006 (the year highly qualified replaced fully certified in OSEP reporting). That year, 88.8\% of SETs were highly qualified. By 2010, that percentage had grown to $94.2 \%$. Also, increased supply of SETs in the reserve pool may enable hard-to-staff schools to hire highly qualified SETs. Although the relationships among higly qualified teacher status, student-teacher ratios, and student outcomes are not well understood, increasing student: teacher ratios are likely to reduce achievement gain, whereas increased representation of highly qualified teachers is likely to have the opposite effect.

Media reports also suggest that the recent decline in demand for SETs is affecting fundamentally how SWDs are educated. In New York City, the Panel on Education Policy recommended that special education class sizes be increased by $20 \%$ in inclusion classes and 25\% in self-contained classes (Hampton, 2011, June 8). In New Haven, Connecticut, the 
Superintendent of Schools proposed increasing caseloads so that the district's special education needs could be met with 25\% fewer SETs (DeMatteo, 2011, June 14). In one coastal North Carolina district (and elsewhere, we suspect), dilution of services has surfaced in a different form. There, paraprofessionals are filling in for SETs (Shah, 2011, May 11). Such practices raise serious questions about the quality of special education supports and the role of SETs in the delivery of services.

Thus, the recent decline in demand for SETs seems to have had an impact on how SWDs are served, and we posit that such change is largely deleterious, a situation that is certain to reinvigorate parent advocacy. With increased student-teacher ratios in special education, parents may look to the courts for assurance that evidence-based IEP services are provided (Archer, 2011, April 29).

\section{SET Preparation}

For special education teacher educators, there is irony in the labor market change. Although we have worked long and hard to eliminate SET shortages, the fact that shortages have been abating (though far from being eliminated) is unsettling. Perhaps those of us in the field never thought seriously about life after persistent high shortage and the consequences of fulfilling our mission to provide a qualified teacher for every special education student. On the other hand, special educators may feel unsettled because of the uncertainty about the force motivating change. We have good will on the part of schools implementing RTI and hypothesized that successful RTI implementation may result in fewer students requiring special education services. However, serving fewer students also reduces costs, and others (e.g., Levenson, 2012) seem to value cost effectiveness more so than improved outcomes. Only time will tell whether the primary goal of RTI implementation has been to help students or reduce 
costs. By contrast, changes in the political landscape are real and current, and many states have implemented or are considering policies that will change teaching fundamentally — the abolition of professional unions and tenure, and pay for performance among them. That teachers are no longer held in the same high esteem they once were is likely to affect both the desirability of a teaching career and the number of undergraduates who enter teacher education.

In the longer term, whether demand for SETs will continue to decline and whether special education will ever employ as many teachers as it has historically remain subject to projections based on uncertain assumptions. However, the potential effects of sustained decadelong decline in demand may be conjectured. Special education teacher education programs are likely to struggle with declining enrollments and ongoing competition from alternative route providers, and programs at public colleges and universities are likely to experience reductions in state support as well. Some teacher education programs may be in jeopardy, especially lowenrollment programs preparing teachers in low incidence disability specializations.

\section{Special Education Policy}

Trends in the demand, supply, and shortage of teachers are in rapid transition and have far-reaching consequences for special education policy. First, policymakers in special education at all levels (federal, state, and local) should carefully monitor the variability in demand for SETs, be cognizant of the range of potentials, and take actions to understand the forces behind this variability and their impacts on the field. Second, with the current decline in demand for SETs, the supply of qualified applicants for teaching positions will likely increase relative to demand in the short term. Qualified individuals from the reserve pool who are unable to secure teaching positions may grow discouraged and seek employment in other fields. The flow from the pipe-line of newly prepared teachers also may diminish due to declining employment 
opportunities. Moreover, enhanced short-term SET supply, relative to demand, should improve the qualifications of the teaching force and should make possible the more equitable distribution of qualified SETs in hard-to-staff schools and positions. Consequently, the economic downturn and the impact it has had on SET employment provide an excellent opportunity for local and state policy makers to consider initiatives to improve the equitable distribution of qualified teachers across schools and assignments and to improve the overall level of qualifications of the local teaching force.

As newly graduated individuals from teacher preparation programs in special education have more difficulty securing teaching appointments in locations and assignments of their choice, enrollments may decline. However, at some point, demand for SETs will rebound, and state and university policy makers would be well advised to avoid hasty decisions regarding retrenchments of teacher preparation capacity. To assist in such decision making, federal and state policy makers must monitor trends in the production and hiring of beginning teachers with the goal of identifying specializations most likely to be in short supply in the intermediate term. Particular attention should be given to low-enrollment programs preparing teachers in lowincidence disability specializations.

Finally, policy makers need to consider that the current decline in demand for SETs may be a function of inadequate funding and that diminished funding might have adverse effects on the best attainable outcomes for SWDs. Clearly, a decline in demand for SETs does not necessarily mean that funding for special education should be reduced. Instead, the focus should be on the provision of sufficient high-quality instructional services for SWDs.

\section{Recommendations}


Our review leads us to make the following recommendations to stakeholders and policy makers charged with ensuring that SWDs receive a free, appropriate public education. Although SET demand has declined, we have not eliminated shortages and not all SWD have access to a highly qualified and effective SETs. We believe that many factors affect the decline in SET demand and recommend that researchers and policy makers identify those that contribute to variability and clarify how such changes impact student outcomes.

In the near term, the current decline in demand for teachers in special education is likely to improve the overall qualifications of the teaching force. Yet, we are in a period of uncertainty about the adequacy of the future supply of SETs and the factors that impact it. Unfortunately, not all states collect appropriate or similar data. We recommend that the field produce hard evidence about teacher supply and demand and annual new hires, monitor teacher supply sources, and prepare short-term, intermediate, and long-term contingency plans for emerging developments. Interventions and policy initiatives effective in reducing the numbers of students needing special education services and facilitating the education of SWDs in general education environments should be implemented at optimal levels. We must ensure SWDs who need additional supports to succeed in the general education classroom receive the evidence-based instructional services they require to succeed, whether the services are provided by GETs or SETs. Students identified with disabilities and needing specialized and intensive educational services must have access to competent and credentialed SETs. Consequently, we recommend that advocates and stakeholders monitor closely the interactions among special education funding, service delivery, disability identification rates, and outcomes for students at risk for and with disabilities.

Our current period of reduced SET demand provides policy makers and local school personnel an opportunity to address inequitable distribution of teacher quality. We believe 
strongly that the reduced demand for SETs, particularly among more prosperous schools and districts, is a market condition that can be leveraged to benefit hard-to-staff, high need schools. We recommend the development of a comprehensive and explicit plan of action that extends beyond financial incentives and field-based professional development and that will facilitate the recruitment and retention of highly qualified and effective teachers for historically disadvantaged schools.

Our history of SET shortages has been a major impetus for the proliferation of alternative routes to certification (Rosenberg, Boyer, Sindelar, \& Misra, 2007). States have responded by endorsing programs that allow rapid, often immediate, entry to the classroom; in addition, 30\% of all alternative route programs have abbreviated training substantially (Rosenberg et al.). Arguably, teacher quality suffered when preparation in the myriad areas needed for success (e.g., instructional supports, behavior management, literacy, etc.) is minimized. With limited funds available to support SET training, state and federal makers must make informed and cautious decisions about what programs to fund.

In this period of reduced demand for SETs, we recommend that teacher educators focus more intently on how best to address two powerful issues related to teacher and teacher preparation quality: (a) reform of general education teacher education as it relates to Tier 1 and 2 instruction within the RTI framework and (b) the unique expertise needed by special educators in the design and delivery of specialized Tier 2 and 3 interventions (Brownell et al., 2010). The 325T program initiated by OSEP serves as a model of how federal support can be leveraged to improve individual teacher preparation programs.

\section{Conclusion}


For the first time in our profession's brief history, we are witnessing a dramatic shift in the demand for SETs. Our goal in this paper was to describe this new trend and explore indicators, explanations, and impacts associated with it. Awareness of these data may challenge traditional notions of the special education teacher marketplace, and we urge serious conversation and study of this important issue. All special education teacher educators are committed to assuring that SWD have access to highly qualified and effective SETs. Only with vigilance and continuous monitoring of credible data can we navigate this changing landscape to ensure an adequate supply. 


\section{References}

Archer, K. (2011, April 29). Parents of special-needs students sue 4 districts. Retrieved from http://www.tulsaworld.com/news/article.aspx?subjectid=11\&articleid=20110429_19_A1

\section{Twenty506481}

Barro, S. M. (1992). Models for projecting teacher supply, demand, and quality: An assessment of the state of the art. In E. E. Bow \& D. M. Gilford (Eds.), Teacher supply, demand, and quality: Policy issues, models, and data bases (pp. 318-329). Washington, DC: National Academy Press.

Barton, R., \& Stepanek, J. (2009). Three tiers to success. Principal Leadership, 9(8), 16-20. Board of Governors of the Federal Reserve System. (2011). Minutes of the Federal Open Market Committee, June 21-22. Retrieved from http://www.federalreserve.gov/monetarypolicy/fomcminutes20110622ep.htm

Boe, E. E. (2006). Long term trends in the national demand, supply, and shortage of special education teachers. The Journal of Special Education, 40, 138-150. doi:10.1177/00224669060400030201

Boe, E. E. (2008). [Number of special education teachers employed in school year 2003-2004]. Unpublished raw data.

Boe, E. E., \& Cook, L. H. (2006). The chronic and increasing shortage of fully-certified teachers in special and general education. Exceptional Children, 72, 443-460.

Boe, E. E., Cook, L. H., Kaufman, M. J., \& Danielson, L. (1996). Special and general education teachers in public schools: Sources of supply in national perspective. Teacher Education and Special Education, 19, 1-16. doi:10.1177/088840649601900102 
Boe, E. E., Cook, L. H., \& Sunderland, R. J. (2007). The prevalence of various aspects of teacher preparation, induction, mentoring, extra support, professional development, and workload factors for beginning teachers in special and general education. (Data Analysis Rep. 2007-DAR1). Philadelphia: University of Pennsylvania, Graduate School of Education, Center for Research and Evaluation in Social Policy.

Boe, E. E., Cook, L. H., \& Sunderland, R. J. (2008). Teacher turnover: Examining exit attrition, teaching area transfer, and school migration. Exceptional Children, 75, 7-31.

Boe, E. E., Cook, L. H., \& Sunderland, R. J. (2009). Trends in the turnover of teachers from 1991 to 2004: Attrition, teaching area transfer, and school migration. (Data Analysis Rep. 2007-DAR2). Philadelphia: University of Pennsylvania, Graduate School of Education, Center for Research and Evaluation in Social Policy.

Brackett, A., Mundry, S., Guckenburg, S., \& Bourexis, P. (2008). An analysis of state data on the distribution of teaching assignments filled by highly qualified teachers in New York schools (Issues \& Answers Report, REL 2008-No. 047). Washington, DC: U.S. Department of Education, Institute of Education Sciences, National Center for Education Evaluation and Regional Assistance, Regional Educational Laboratory Northeast and Islands. Retrieved from http://ies.ed.gov/ncee/edlabs/regions/northeast/pdf/REL_2008047_sum.pdf

Brownell, M. T., Sindelar, P. T., Kiely, M. T., \& Danielson, L. C. (2010). Special education teacher quality and preparation: Exposing foundations, constructing a new model. Exceptional Children, 76, 357-377.

Bureau of National Affairs (2008). Job absence \& turnover: 4th quarter 2007. Bulletin to Management (Vol. 59). Washington, DC: Author. 
Bureau of National Affairs (2011). Job absence \& turnover: 4th quarter 2010. Bulletin to Management (Vol. 61). Washington, DC: Author.

Cavanagh, S. (2011). States battling over education budgets at fiscal year's end. Education Week. Retrieved from http://www.edweek.org/ew/articles/2011/06/22/36

Congressional Budget Office. (2011). Budget and Economic Outlook: Fiscal Years 2011 to 2012. Retrieved from http://www.cbo.gov/doc.cfm?index=12039

Cook, L. H., \& Boe, E. E. (2007). National trends in the sources of supply of teachers in special and general education. Teacher Education and Special Education, 30, 217-232. doi:10.1177/088840640703000402

Cullen, J. (2003). The impact of fiscal incentives on student disability rates. Journal of Public Economics, 87, 1557-1589.

DeMatteo, A. (2011, June 14). Teacher ranks may be thinned in North Haven. Post Chronicle. Retrieved from http://www.ctpostchronicle.com/articles/2011/06/14/news/doc4df746c8af2ec714514159. prt

Dexter, D. D., Hughes, C. A., \& Farmer, T. W. (2008). Responsiveness to intervention: A review of field studies and implications for rural special education. Rural Special Education Quarterly, 3(4), 3-9.

Ellerson, N. (2010a). Surviving a thousand cuts: America's public schools and the recession. Arlington, VA: American Association of School Administrators. Retrieved from http://www.aasa.org/uploadedFiles/Policy_and_Advocacy/files/AASAThousandCutsFIN AL121610.pdf 
Ellerson, N. (2010b). Cliff hanger: How America's public schools continue to feel the impact of the economic downturn. Arlington, VA: American Association of School Administrators. Retrieved from http://www.aasa.org/uploadedFiles/Policy_and_Advocacy/files/CliffHangerFINAL(1).pd $\underline{f}$

Executive Office of the President (2012). Investing in our future: Returning teachers to the classroom. Washington, DC (author).

Federal Register. (2010). Secretaries priorities for discretionary grant programs (Notice of Proposed Priorities). Federal Register 75 (August 5, 2010) p. 47284-47284-47291.

Florida Department of Education. (2009). New hires in Florida public schools fall 1999 through fall 2008. Tallahassee, FL: Office of Research and Evaluation.

Fuchs, D., Fuchs, L. S., \& Compton, D. L. (2012). Smart RTI: A next-generation approach to multilevel prevention. Exceptional Children, 78, 263-279.

Georgia Professional Standards Commission. (2010, March 23). Special education teachers supply and demand. Retrieved from http://public.doe.k12.ga.us/DMGetDocument.aspx/Sp_Ed_Teacher_Recruit_Retention_P $\underline{\text { SC.pdf?p=6CC6799F8C1371F6BA6F4D8B9AD156797748F699C3B4FCEAE7CBF6C }}$ $\underline{\text { A7E5155C4\&Type }=\mathrm{D}}$

Graham, K. A. (2011, August 16). Philly school agrees to settlement on teacher layoffs. Retrieved from: http://www.philly.com/philly/blogs/school_files/Philly-School-Districtagrees-to-settlement-on-teacher-layoffs.html 
Hampton, E. (2011, June 8). As special education class sizes increase, community members and advocates grow worried. Retrieved from http://bed-stuy.patch.com/articles/as-specialeducation-class-sizes-increase-community-members-and-advocates-grow-worried

Helms, A. D. (2011, July 5). Teacher turnover hits record low in CMS, N.C. Charlotte Observer. Retrieved from http://www.charlotteobserver.com/2011/07/05/2429169/teacher-turnover-hitsrecord-low.html

Hernandez, J. C. (2009, May 10). For many teachers, a famously fertile market dries up overnight. The New York Times. Retrieved from http://www.nytimes.com/2009/05/11/nyregion/11teachers.html

Hess, F., \& Downs, W. (2010, November). K12 budget picture: Lean years ahead. Washington DC: American Enterprise Institute. Retrieved from http://www.aei.org/outlook/101002 Hu, W. (2010, May 19). Teachers facing weakest market in years. The New York Times., Retrieved from http://www.nytimes.com/2010/05/20/nyregion/20teachers.htmlJohnson,

Johnson, H. A. (2003). U. S. deaf education teacher preparation programs: A look at the present and a vision for the future (COPSSE Document No. IB-9). Gainesville, FL: University of Florida, Center on Personnel Studies in Education. Retrieved from http://copsse.education.ufl.edu/copsse/docs/IB-9/1/IB-9.pdf

Keigher, A. (2010). Teacher Attrition and Mobility: Results From the 2008-09 Teacher Followup Survey (NCES 2010-353). U.S. Department of Education. Washington, DC: National Center for Education Statistics. Retrieved from http://nces.ed.gov/pubsearch .

Keaton, P. (2012). Public Elementary and Secondary School Student Enrollment and Staff Counts From the Common Core of Data: School Year 2010-11 (NCES 2012-327). U.S. Department of Education. Washington, DC: National Center for Education Statistics. 
Kober, N., \& Rentner, D. S. (2011). Strained schools see bleak future: Districts foresee budget cuts, teacher layoffs, and a slowing of education reform efforst. Center on Education Policy. Retrieved from http://cep-dc.org

Lauritzen, P., \& Friedman, S.J. (1993). Meeting the supply/demand requirements of the Individuals with Disabilities Education Act. Teacher Education and Special Education, 16, 221-229. doi:10.1177/088840649301600304

Levenson, N. (2012, September). Boosting the Quality and Efficiency of Special Education. Washington, DC: The Fordham Foundation. Retrieved from http://www.edexcellencemedia.net/publications/2012/20120905BoostingtheQualityandEf ficiencyofSpecialEducation/20120905BoostingtheQualityandEfficiencyofSpecialEducati on20120905BoostingtheQualityandEfficiencyofSpecialEducationFinal.pdf

Maryland State Department of Education. (2010). Maryland teacher staffing report: 2010 2012. Baltimore, MD: Author.

McCord, R. S., \& Ellerson, N. M. (2009). Looking back, looking forward: How the economic downturn continues to impact school districts. Arlington, VA: American Association of School Administrators. Retrieved from http://www.aasa.org/uploadedFiles/Resources/files/LookingBackLookingForward.pdf

McLeskey, J., Landers, E., Williamson, P., \& Hoppey, D. (2010). Are we moving toward educating students with disabilities in less restrictive environments? The Journal of Special Education. DOI: 10.1177/0022466910376670

Minow, M. L. (2001). Funding mechanisms in special education. Wakefield, MA: National Center on Accessible Instructional Materials. Retrieved from http://aim.cast.org/learn/historyarchive/backgroundpapers/funding_mechanisms 
National Center on Education Statistics (NCES). (1997). Issue Brief: The impact of the baby boom echo on U. S. public school enrollments. NCES 98-039. 1997. Retrieved from http://nces.ed.gov/pubs98/web/98039.asp

National Center on Education Statistics (NCES). (2011). Schools and staffing survey (SASS). Retrieved from http://nces.ed.gov/surveys/sass/tables/tfs0809_021_cf1n.asp

Office of Special Education Programs (OSEP). (1995). Annual report: To assure a free appropriate public education for all children with disabilities: 1995. Retrieved from http://www.ed.gov/pubs/OSEP95AnlRpt/ch5b.html

Rosenberg, M. S., Boyer, K. L., Sindelar, P. T., \& Misra, S. (2007). Alternative route programs to certification in special education: What we know about program design, instructional delivery, and participant characteristics. Exceptional Children, 73, 224-241.

Roza, M., Lozier, C., \& Sepe, C. (2010, March 16). K-12 job trends amidst stimulus funds: Early findings. Seattle, WA: University of Washington, Center on Reinventing Public Education. Retrieved fromhttp://www.crpe.org/cs/crpe/download/csr_files/rr_crpe_jobtrends_rr8_mar10.pdf

Shah, N. (2011, May 11). As the "Funding Cliff” nears, districts cut special education jobs. Education Week, 30(30), 8-9.

Snyder, T.D., \& Dillow, S.A. (2011). Digest of Education Statistics 2010 (NCES 2011-015). Washington, DC: National Center for Education Statistics, Institute of Education Sciences, U.S. Department of Education. Retrieved from http://nces.ed.gov/pubs2011/2011015.pdf 
Thomas, R. (2010, December 17). Teacher layoffs hit special education. Retrieved from http://www.wilx.com/news/headlines/Teacher_Layoffs_Hit_Special_Education_1121038 34.html

Torgesen, J. K. (2009). The response to intervention instructional model: Some outcomes from a large-scale implementation in reading first schools. Child Development Perspectives, 3(1), 38-40. doi:10.1111/j.1750-8606.2009.00073.x

U. S. Department of Education. (2010). American Recovery and Reinvestment Act, Section 1512 Quarterly Reporting through June 30, 2010 -- by State. Retrieved from http://www2.ed.gov/policy/gen/leg/recovery/spending/impact4.html

VanDerHeyden, A. M., Witt, J., \& Gilbertson, D. (2006). A multi-year evaluation of the effects of a Response to Intervention (RTI) model on identification of children for special education. Journal of School Psychology, 45, 225-256. doi:10.1016/j.jsp.2006.07.003

Vaughn, S., Wanzek, J., Linan-Thompson, S., \& Murray, C. S. (2007). Monitoring response to supplemental services for students at risk for reading difficulties: High and low responders. In S. R. Jimerson, M. K. Burns, \& A. M. VanDerHeyden (Eds.), Handbook of response to intervention: The science and practice of assessment and intervention (pp. 234-243). New York, NY: Springer.

Vellutino, F. R., Scanlon, D. M., Small, S., \& Fanuele, D. P. (2006). Response to intervention as a vehicle for distinguishing between children with and without reading disabilities: Evidence for the role of kindergarten and first-grade interventions. Journal of Learning Disabilities, 39, 157-169. doi: 10.1177/00222194060390020401

Vogt, A. (2010, May 4). New AASA survey finds 275,000 education jobs in peril. Arlington, VA: American Association of School Administrators. Retrieved from 
http://www.aasa.org/content.aspx?id=13246\&terms=New+AASA+survey+finds+275\%2 $\underline{\text { c000+education+jobs+in+peril }}$

Watson, S. (2001). Recruiting and retaining teachers: Keys to improving the Philadelphia Public Schools. Retrieved from Eric database. (ED480407)

West, J. E., \& Whitby, P. J. S. (2008). Federal policy and the education of students with disabilities: Progress and the path forward. Focus on Exceptional Children, 41(3), 1-16.

Zirkel, P. A., \& Thomas, L. B. (2010). State laws and guidelines for implementing RTI. Teaching Exceptional Children, 43(1), 60-73. 


\section{Footnotes}

${ }^{2}$ Our analyses are limited to special education teachers of students with disabilities defined by OSEP as the number of students ages 6 through 21 served under IDEA (annual Tables 1-3 at www.ideadata.org).

${ }^{3}$ The demand for teachers occurs at the level of the local school district that has the authority to create and fund teaching positions. Aggregating the demand for teachers employed by all districts within a state provides total teacher demand in public schools at the state level. Similarly, aggregating the demand for teachers in the 50 states, the District of Columbia, the Bureau and Indian Affairs, and the 5 territories, represents the national demand for teachers in public schools. For any year, total demand is the total number of employed SETs during a prior year plus growth, or reduction, in the total number of funded teaching positions in special education in the succeeding year.

${ }^{4}$ Data on the number of SETs in New Jersey was missing from Table 3-2 for 2008 (at www.ideadata.org). Consequently, we imputed the missing number by computing the mean number of SETs reported for New Jersey in 2007 and 2009. The data point for total demand in Figure 1 for 2008 includes this imputed number $(18,200)$.

${ }^{5}$ We computed the number of full-time equivalent GETs employed annually by subtracting the number of full-time equivalent SETs (see annual Tables 3-2 at www.ideadata.org) from the total number of full-time equivalent public school teachers (Snyder \& Dillow, 2011; Keaton, 2012).

${ }^{6}$ The annual demand for SETs, as measured at the district level, is the sum in any one year of SETs (a) who have left teaching employment entirely, (b) who have switched to teaching 
positions in general education, (c) who have moved to teaching positions in a different district; and (d) the growth or reduction in teaching positions for SETs. 
Table 1: High and Low National SET and SWD Projections for 2020

\begin{tabular}{|l|r|r|r|}
\hline & 2008 & \multicolumn{2}{|c|}{2020 Projection } \\
& Actual & High & \multicolumn{1}{c|}{ Low } \\
\hline \hline U.S. Public PK-12 Students (Millions) $^{\mathrm{a}}$ & 49.3 & 52.7 & 52.7 \\
SWD per 100 U.S. Public PK-12 Students $^{\mathrm{b}}$ & 12.0 & 11.5 & 10.0 \\
SWD (Millions) & 5.9 & 6.0 & 5.2 \\
SET per 100 SWD $^{\mathrm{c}}$ & 6.2 & 6.5 & 5.5 \\
Total SET (Thousands) & 364 & 392 & 288 \\
Remaining 2008 SET (Thousands) $^{\mathrm{d}}$ & 364 & 164 & 164 \\
2020 SET Hired after 2008 (Thousands) & & 228 & 124 \\
Annual SET Hires 2016-2020 (Thousands) $^{\mathrm{e}}$ & & 55 & 30 \\
\hline
\end{tabular}

a 2008 value from NCES at http://nces.ed.gov/ccd. 2020 Projection from Hussar, and Bailey. (2011).

b High projection assumes SWD/ENR falls by 0.1 annually for 5 years . Low projection assumes SWD/ENR falls by 0.2 annually for 10 years.

c We estimate the proportion of 2008 teachers of each age from 20 to 75 from the December 2008 Survey of Income and Program Participation. We use all teachers, (Singer 1993 finds SETs and GETs have similar career paths, and the age distribution is statistically similar in this data) and apply an endpoint adjusted Hanning smoother. We assume the following attrition rates by age: under 25, 9.3\%; 25-29, 9.2\%; 30-39, 8.4\%, 40-49, 3.9\%, 50-59, 4.7\%, 60-64, 18.8\%, 65-74, 28.6\%; 75, 100\%. 2007-2008 SASS and 2008-2009 TFS attrition rates are available from NCES (http://nces.ed.gov/). The breakdown from the 1990-1991 SASS and 19911992 TFS for the following groups are: under 25, 25-29, 30-39, 40-49, 50-59, 6064, and 65 and over (http://ritter.tea.state.tx.us/research/pdfs/prr6.pdf), which we scale to the recent but broad NCES group totals.

${ }^{\mathrm{d}}$ Assumes transfers from special to general education balance transfers in the other direction, as has been true historically.

${ }^{\mathrm{e}}$ Assumes annual attrition of $9.3 \%$ for new hires after each of their first 4 years. 


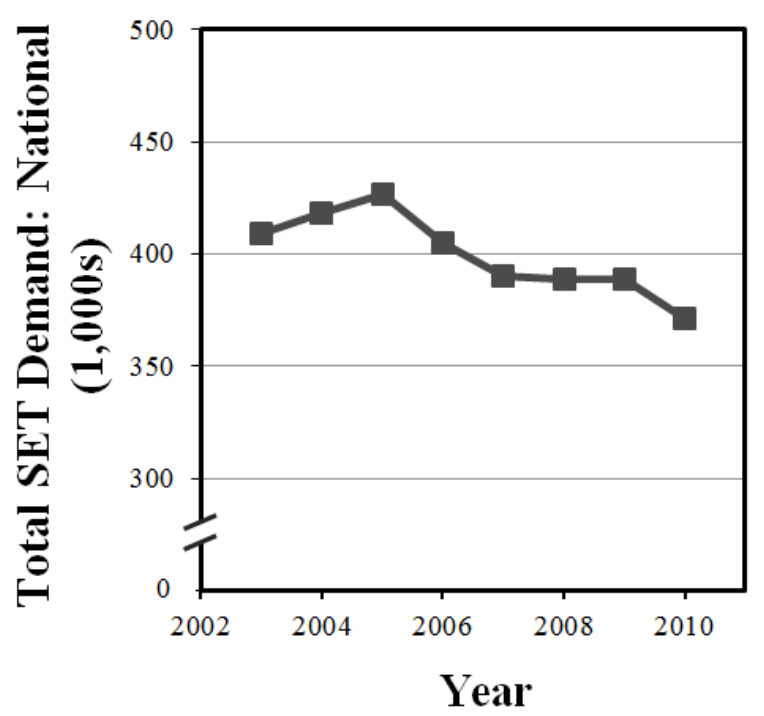

Figure 1. Total demand for SETs at the national level by October of each year. Data from the Data Accountability Center of OSEP, USDE. 


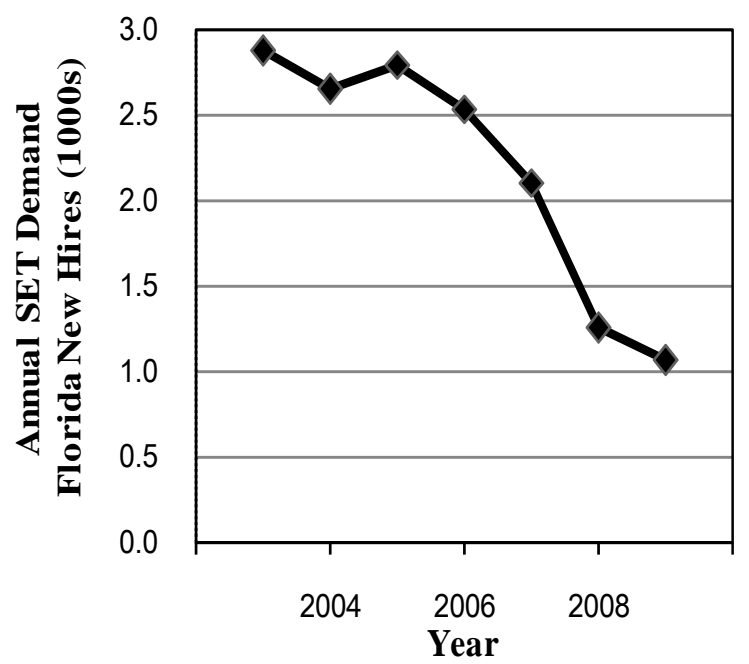

Figure 2. Annual demand for newly-hired SETs in Florida by October of each year. Data from the Office of Research and Evaluation, Florida Department of Education. 


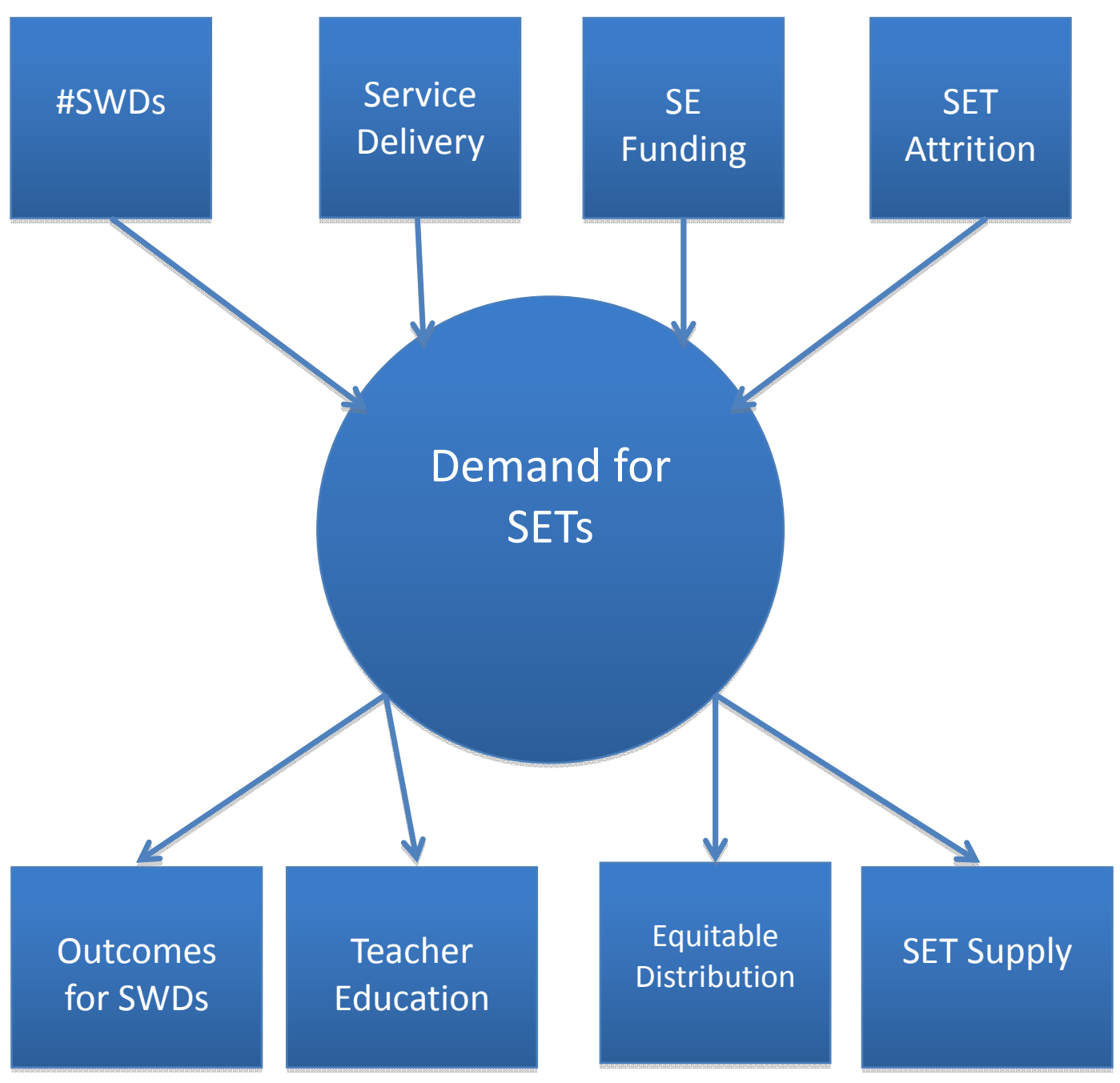

Figure 3. Conceptual framework of explanations of variability in SET demand and its potential impacts. 


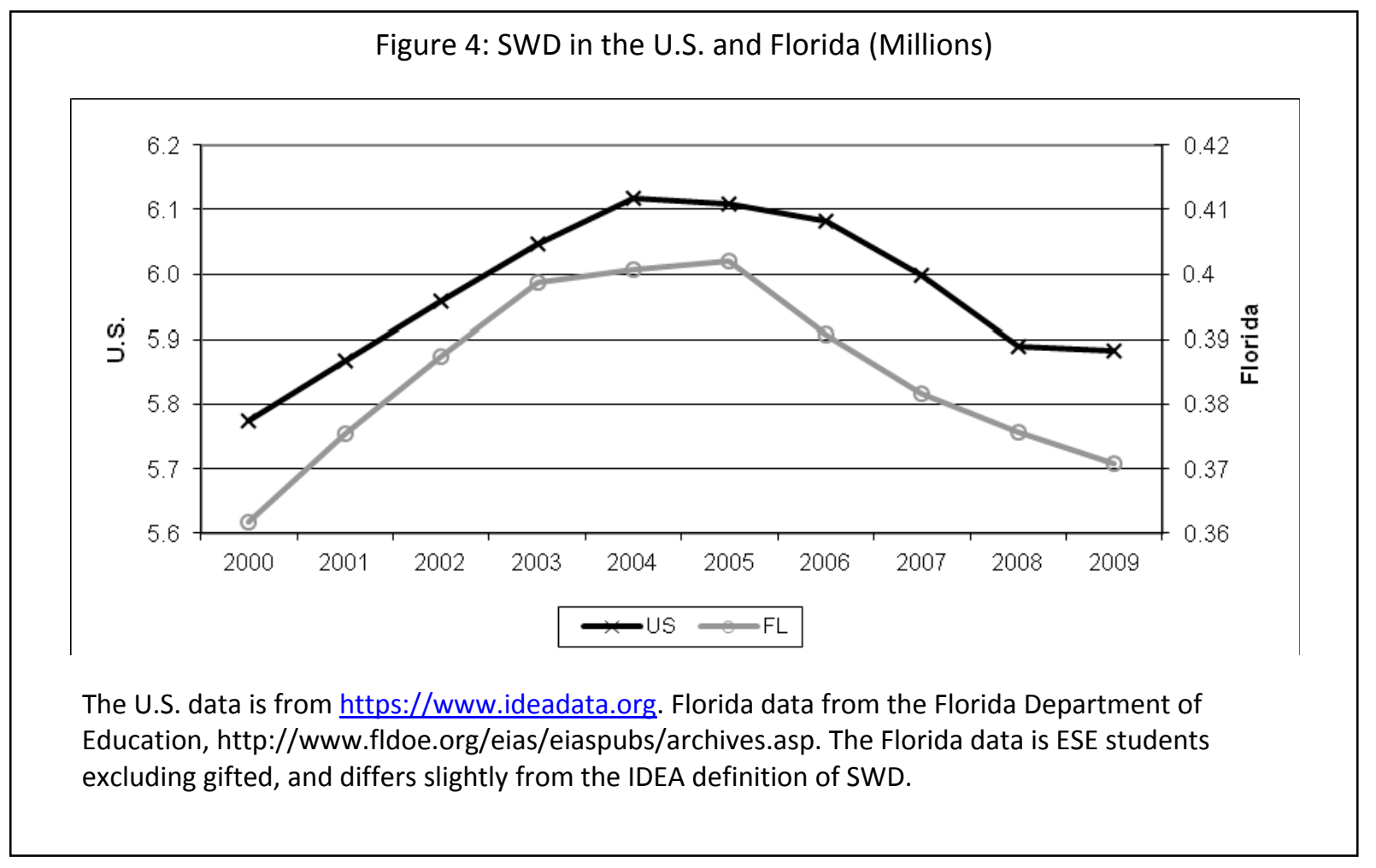

